\title{
Battery Recycling Technologies: Recycling Waste Lithium Ion Batteries with the Impact on the Environment In-View
}

\author{
Oluwatosin Emmanuel Bankole (Corresponding author) \\ School of Chemistry and Chemical Engineering, Southeast University, Nanjing 211189 , \\ China \\ Department of Chemistry, College of Natural Sciences, Crawford University, P.M.B \\ 2001, Atan-Agbara Road, Ogun State, Nigeria \\ E-mail: bantosinemma@yahoo.co.uk
}

Chunxia Gong

E-mail: gong417@sina.com

Lixu Lei

School of Chemistry and Chemical Engineering

Southeast University, Nanjing 211189, China

E-mail: lixu.lei@seu.edu.cn

Received: February 14, 2013 Accepted: March 18, 2012 Published: June 24, 2013

doi:10.5296/jee.v3i1.3257ＵRL: http://dx.doi.org/10.5296/jee.v3i1.3257

\begin{abstract}
This survey is to review the advancement recorded so far in the lithium-ion battery recycling technologies in compliance with environmental laws. Amongst many of the technologies used to date, the best is the use of simple but scale-up dissolution technology involving non-toxic suitable organic solvents that can effectively dissolve toxic binder, PVdF in battery to avoid much pollution. Pollution through the hydrolysis of $\mathrm{LiPF}_{6}$ from the lithium-ion battery can also be minimized through conversion to useful compounds instead of using
\end{abstract}




\section{Macrothink}

Journal of Environment and Ecology ISSN 2157-6092 2013, Vol. 4, No. 1

virgin materials for the synthesis. More environmentally friendly recycling technologies are still needed to meet the demands for materials, for scale-up processes and in compliance with environmental laws.

Keywords: Environmental pollution, Waste lithium-ion battery, Recycling, Technologies 


\section{Introduction}

The environmental pollution caused by the valuable chemical components such as cobalt, copper, lithium, mixture of organic electrolyte and salts of either low quality or spent lithium-ion batteries ( $\mathrm{LiBs}$ ) deposited into the environments necessitates responsive recovery technologies. Since Sony made the first commercial lithium-ion cell in 1991, it has been accorded more attention being superior to other types of batteries in terms of energy density, which is a critical parameter for portable electronics as well as hybrid and electric vehicles. Lithium ion batteries are the systems preferred as electrochemical power sources in portable batteries segment such as mobile telephones, personal computers, video-cameras and other modern-life appliances as well as in vehicles with electric drive due to its favorable characteristics (Contestabile et al., 2001; Gaines, 2011; Nan et al., 2005; Wang et al., 2011). As LiBs progressively dominate, the amounts of valuable chemical components that will be deposited will be proportional to the number of LiBs used after their life-span has expired. Therefore, recycling that constitutes the most generally acceptable environmentally friendly method of managing these wastes must be taken serious, to minimize environmental toxicity, for economic gains and reduction in dependence on foreign resources or on virgin materials for productions in the industry as well as for sustainability of the natural resources (Contestabile et al., 1999; Dewulf, et al., 2010; Graham-Rowe, 2010; Hitachi, 2011; Kumar, 2011; Wang et al., 2011). The methods could be on the laboratory scale, industrial or commercial scale level. These as-recovered metals or their respective compounds (cobalt, lithium, manganese, and nickel) are not only valuable metals but are alternative precursors for new batteries formulations. Thus, several attempts have been made to review the old processes considered green and non-green chemistries to either improve on the existing ones or propose new recovery processes that are considered simple and of industrial-scale (Kondás et al, 2006; Nan et al., 2005). However, the cells used in cell phones and laptops are not fully recycled and consequently causing unsustainable open loop in the industrial cycle (Wang et al., 2011).

Although according to the U.S. government, spent LiBs have been classified as non-environmentally hazardous wastes or rather call "green batteries" and thus safe for disposal in the normal municipal waste stream unlike other battery chemistries that contain $\mathrm{Cd}, \mathrm{Pb}$ or $\mathrm{Hg}$, the presence of flammable and toxic elements or compounds may make their safe disposal to become a serious problem. For instance, the mixture of dimethyl carbonate (DMC) and ethylene carbonate (EC) used as solvent is flammable, while the polyvinylidene fluoride (PVDF) used as binder irrespective of its percentage in the battery formulation is toxic when burns consequent to the release of gaseous HF. Besides, the NMP commonly used as a solvent for the electrode active materials (cathode and anode) fabrication during slurry preparation has been reported as toxic and therefore environmentally incompatible (Alfonso et al., 2004; Castillo et al., 2002; Mitchell, 2006; Robert, 2000; Roth and Orendorff, 2012; Wang et al., 2011). As there is a general saying and belief that "health is wealth", similarly, "healthy environment is a wealthy environment". On the other hand, "polluted environment is an unhealthy and un-wealthy environment". Therefore, recycling is of great importance to save our immediate environment and for waste management sustainability. 


\section{Macrothink}

\section{Structural Composition of Lithium-Ion Battery}

All batteries consist of cathode, anode, electrolyte mixture and separator. The cathode has the aluminium foils coated with a mixture of the active material, $\mathrm{LiCoO}_{2}$ or $\mathrm{LiNi}_{1 / 3} \mathrm{Mn}_{1 / 3} \mathrm{Co}_{1 / 3} \mathrm{O}_{2}$ depending on the type, PVdF or PTFE, carbon graphite, while the anode is a copper foil coated with blended slurry of carbon graphite and PVdF or PTFE.

The electrolyte mixture consists of the water-proned electrolyte salt, $\mathrm{LiPF}_{6}$ and organic solvents dissolved in varying ratios such as $1: 1: 1(\mathrm{v} / \mathrm{v})$ for $1 \mathrm{M} \mathrm{LiPF}_{6}$, dimethyl carbonate (DMC) and ethylene carbonate (EC) respectively. In addition, other lithium salts used for lithium-ion battery are $\mathrm{LiAsF}_{6}, \mathrm{LiClO}_{4}$, and $\mathrm{LiBF}_{4}$, while the organic solvents among others are propylenecarbonate with dimethoxyethane (PC-DME), $\gamma$-butyrolactone with tetrahydrofuran (BL-THF) and dioxolane (1, 3-D) according to Contestabile et al (1999).

The separator is a non-conductor that separates the two electrodes from each other. The structure of a cylindrical lithium-ion battery according to Nishi (2001) is represented in Figure 1.

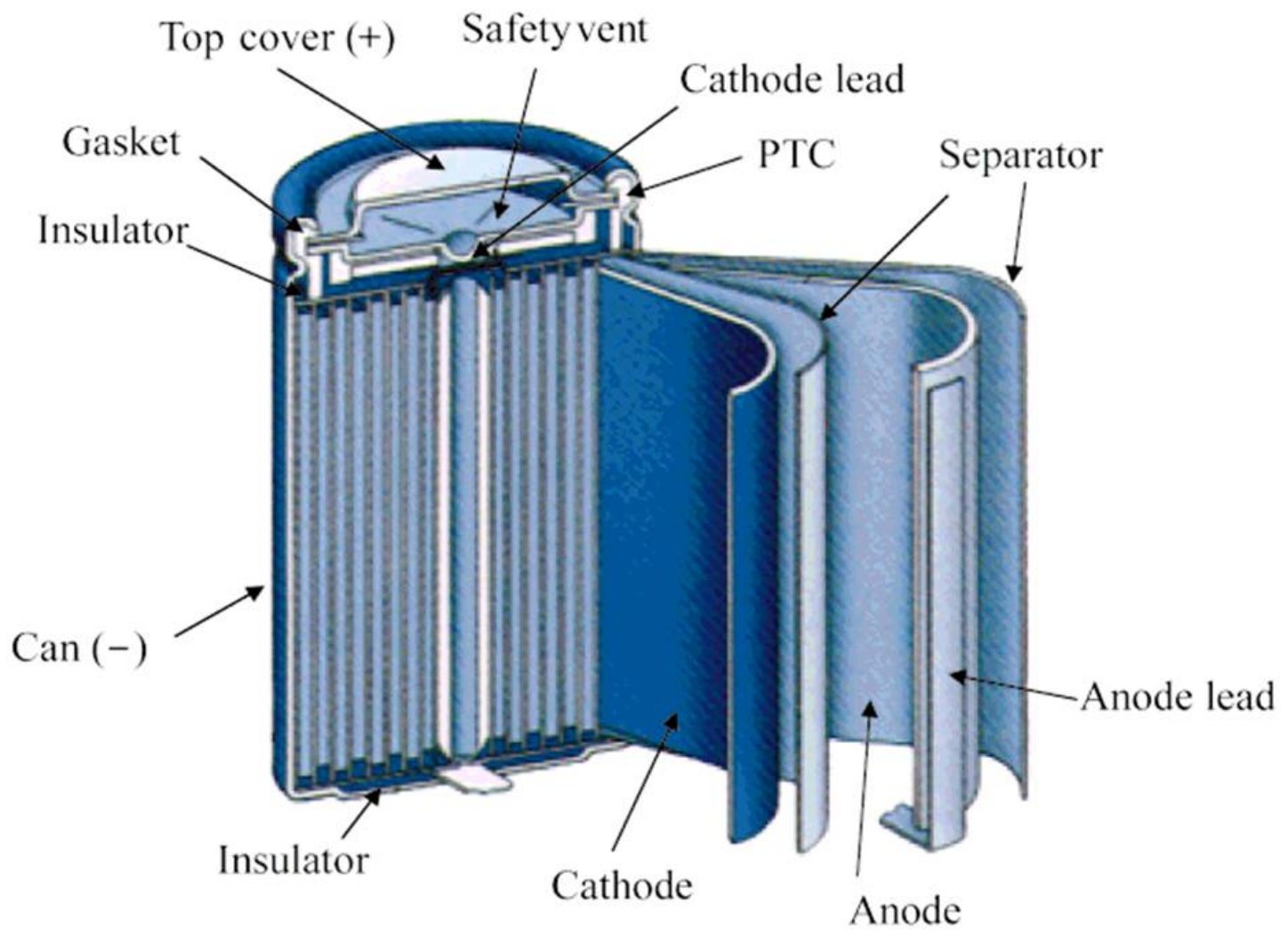

Figure 1. The structure of a cylindrical lithium-ion battery

\subsection{The Chemical Reaction of a Typical Lithium-Ion Battery}




\section{Macrothink}

Lithium ions move from the negative electrode to the positive electrode during the discharge process through the nonaqueous electrolyte and separator diaphragm and then undergo reversible reaction when charging (Figure 2). The ionic chemical reactions are shown in equations 1-3.

The cathodic half reaction:

Discharge

$\mathrm{LiMO}_{2} \longrightarrow \mathrm{Li}_{1-x} \mathrm{MO}_{2}+x \mathrm{Li}^{+}+x \mathrm{e}^{-}$

Charge

The anodic half reaction:

Discharge

$$
x \mathrm{Li}^{+}+x \mathrm{e}^{-}+6 \mathrm{C} \underset{\text { Charge }}{\rightleftarrows} \mathrm{Li}_{x} \mathrm{C}_{6}
$$

The overall reaction:

Discharge

$$
\mathrm{LiMO}_{2}+6 \mathrm{C} \underset{\text { Charge }}{\rightleftarrows} \mathrm{Li}_{1-x} \mathrm{MO}_{2}+\mathrm{Li}_{x} \mathrm{C}_{6}
$$

Where $\mathrm{M}$ reprersents $\mathrm{Mn}, \mathrm{Ni}$ or Co depending on the cathode active material. 


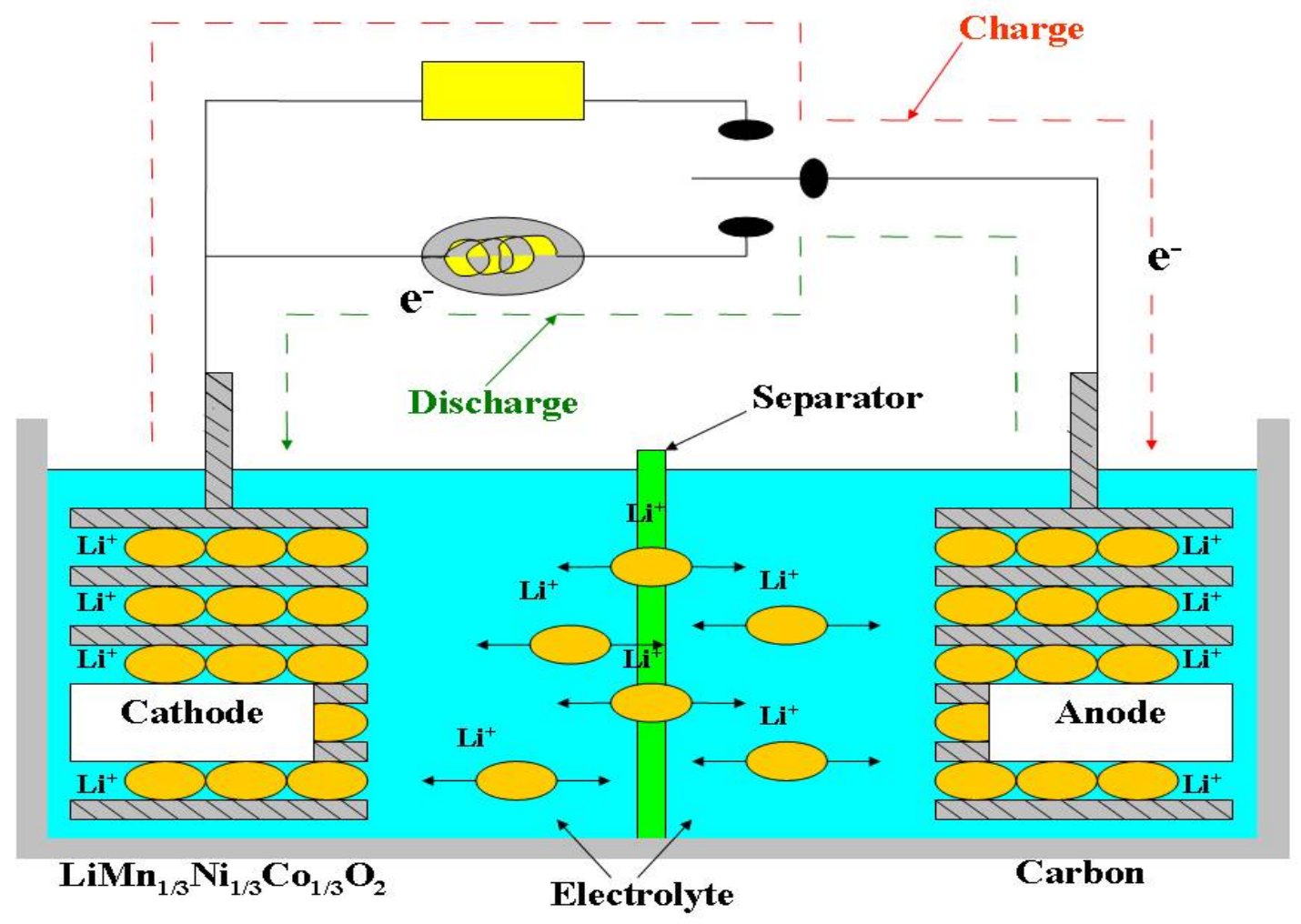

Figure 2. Schematic diagram of the chemical reaction of a lithium-ion battery

\section{Processes for Recovery of Lithium Ion Batteries}

According to $\mathrm{Xu}$ et al (2008), recycling technologies, irrespective of the processes must amongst others achieve the reduction in the volume of the scraps or cases, selective separation of the valuable components. The physical and chemical processes are generally the two categories of processes employed in the laboratory and industry to recycle all kinds of batteries.

\subsection{Physical Processes}

The physical processes are generally dissolution, manual or mechanical separation and pyrolysis. For instance, Contestabile et al (1999) and Bankole and Lei (2013) extracted the electrolyte solution into organic solvents such as ethanol or iso-butylalcohol/water after manually or mechanical dismantling LiBs and this enhanced reduction in the environmental pollution caused by the hydrolysis of electrolyte salt, $\mathrm{LiPF}_{6}$ and also the toxic electrolyte mixture. Interestingly, innovative conversion of $\mathrm{LiPF}_{6}$ to useful compound such as $\mathrm{Li}_{2} \mathrm{SiF}_{6}$ was achieved for the first time (Bankole and Lei, 2013).

\subsubsection{Hydrometallurgical Process}

In hydrometallurgical method, mechanical separation was employed as pretreatment by subjecting LiBs to skinning, crushing removing of crust, sieving and separation of both anode and cathode material for easy recovery of the valuable components of the batteries (Xu et al., 2008; Zhou et al., 2010). However, safety precautions are required due to flammability of the electrolyte mixture (Roth and Orendorff, 2012). Although the stress in manual separation will 
be reduced, the components of the batteries may not be fully separated from one another due to the structural arrangement of the LiBs (Xu et al., 2008).

\subsubsection{Dissolution Process}

This process recently dominates and enhances effectiveness with maximum recovery of valuable components from batteries. The adhesive force from the PVdF holding the electrode active materials (anode and cathode) unto the current collectors is weakened. Therefore, the choice of suitable organic solvents capable of dissolving the binder, PVdF or PTFE becomes very important during recovery processes. Among these suitable solvents that have already been tested and found effective are N, N-dimethylformamide (DMF), N, N-dimethyl acetamide (DMAC), N-methylpyrrolidone (NMP) and dimethylsulfoxide (DMSO) with their order of effectiveness in dissolving the adhesive investigated. For instance, $\mathrm{LiCoO}_{2}$ was recovered from LiBs with the solubility of PVdF in the first three solvents recorded as DMAC > DMF > NMP (Zhou et al., 2010). N-methylpyrrolidone separated both $\mathrm{LiMn}_{1 / 3} \mathrm{Ni}_{1 / 3} \mathrm{Co}_{1 / 3} \mathrm{O}_{2}$ and $\mathrm{LiCoO}_{2}$, from LiBs at $40{ }^{\circ} \mathrm{C}$ for 15 minutes and at $100{ }^{\circ} \mathrm{C}$ for $1 \mathrm{~h}$, respectively (Contestabile et al., 2001; Li et al., 2007). Although the powders were effectively recovered, the cost of buying $1 \mathrm{~L}$ of NMP which is about $\$ 207.90$ makes its application not cost-effective and suitable for a large scale recovery operation (Sigma-Aldrich 2011; Xu et al., 2008). Among all these solvents, DMSO used at $60{ }^{\circ} \mathrm{C}$ for 85 minutes could be the most suitable for its cheapness ( $\$ 144.54 / \mathrm{L}$ ), non-toxicity and environmental safety (MTI Corporation, 2009; Sigma-Aldrich 2011). Moreover, the clean and shiny current collectors (Aluminium foils) obtained after the separation could be used for other applications in the laboratory and industries. The flow-sheet for the recycling of LiBs by dissolution method is shown in Figure 3.

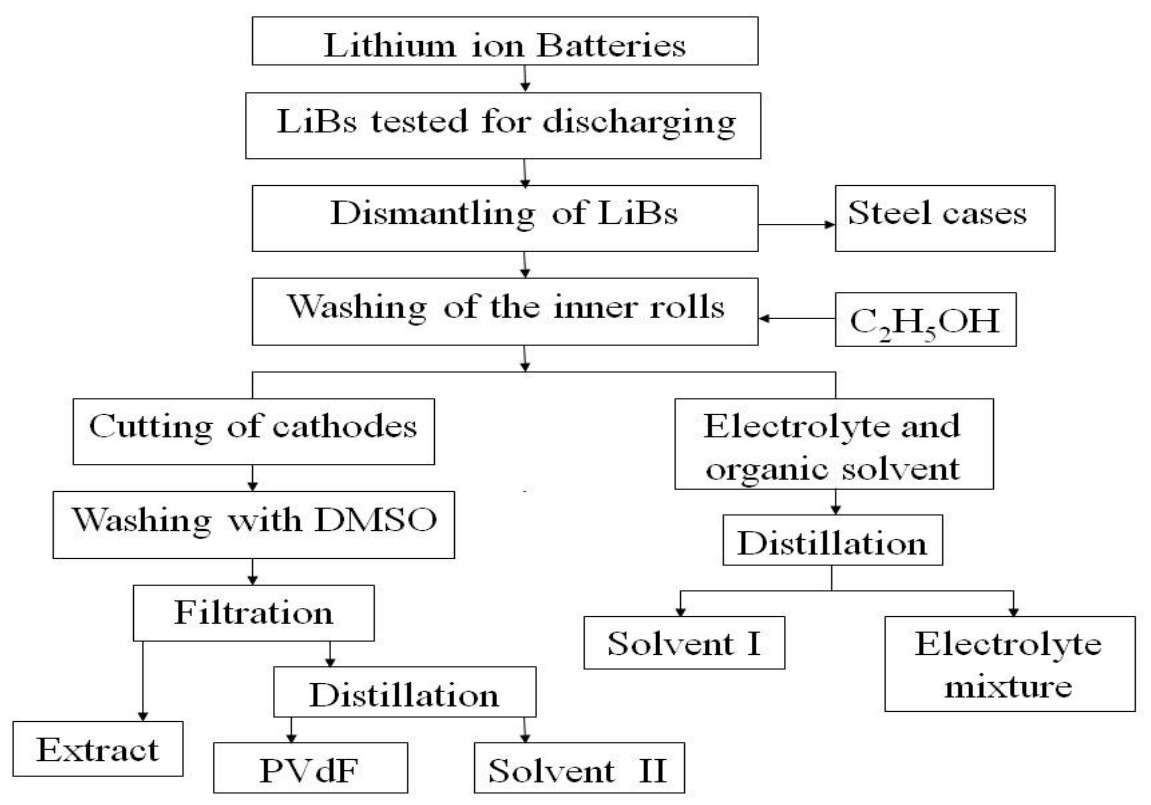

Figure 3. Flow sheet for the recovery of valuable components from LiBs by dissolution process 


\subsubsection{Pyrolysis or Pyrometallurgical Process}

The name comes from the two words "pyro" and "lysis" meaning "fire" and "decomposition", respectively. Therefore, this process decomposes the components of the LIBs by heating to high temperatures under heat and pressure. Pyrometallurgical process has been associated with high air emission of dioxins, chloride compounds and mercury, and therefore requires strict standard for air filtration systems to avoid pollution. It was used as pre-treatment for waste batteries before leaching process, especially to remove $\mathrm{Hg}$, papers and plastics under a controlled atmosphere (Bernardes et al., 2004; Johnson and Derrick, 2010; Pietrelli et al., 2005)

\subsection{Chemical Processes}

The chemical processes are mainly hydrometallurgical methods involving acid or base leaching, solvent extraction, chemical precipitation, bioprocess and electrochemical process or combination of the processes. The multiple-steps will consume more chemicals.

\subsubsection{Hydrometallurgical Processes}

The scraps of the spent LiBs were put in either acid or alkaline solution to dissolve the metallic fraction of the batteries to recover valuable components (Bernardes et al., 2004). Hydrometallurgical was used on the basis of its simplicity, environmentally friendly due to waste water and air emission minimization, adequate recovery of valuable metals with high purity and low energy requirements ( $\mathrm{Li}$ et al., 2010a, 2010b; Pietrelli et al., 2005). For instance, cobalt-containing slag was treated through hydrometallurgical process by Lain (2002) and Espinosa et al (2004).

This process also used the mixture of $\mathrm{H}_{2} \mathrm{SO}_{4}$ and $\mathrm{H}_{2} \mathrm{O}_{2}$ to recover $\mathrm{Li}$ and Co from LiBs and achieved full recovery of the metals within $10 \mathrm{~min}$ at $75{ }^{\circ} \mathrm{C}$ with an agitation of $300 \mathrm{rpm}$. However, the thermal pretreatment of $\mathrm{LiCoO}_{2}$ particles to remove carbon and organic binder before chemical leaching significantly reduced the leaching efficiency. Also, $\mathrm{LiPF}_{6}$ decomposed into lithium fluoride and phosphorus pentafluoride during crushing process (Shin et al., 2005).

Also, with an enhanced leaching efficiency, mixture of an easily degradable organic acid DL-malic acid and $\mathrm{H}_{2} \mathrm{O}_{2}$ was used to recover $\mathrm{Co}$ and Li from LiBs (Li et al, 2010a). Instead of DL-malic acid with $\mathrm{H}_{2} \mathrm{O}_{2}$, both $\mathrm{Co}$ and $\mathrm{Li}$ were effectively recovered using citric acid and $\mathrm{H}_{2} \mathrm{O}_{2}$ (Li et al., 2010b). Kang et al (2010a) leached cobalt-containing powder from LiBs with $\mathrm{H}_{2} \mathrm{SO}_{4}$ and $\mathrm{H}_{2} \mathrm{O}_{2}$ to recover cobalt sulfate, while addition of oxalic acid to the filtrate from another powder produced crystalline cobalt oxalate, which was then heated to produce $\mathrm{Co}_{3} \mathrm{O}_{4}$ (Kang et al., 2010b). Zhang et al (1998) recovered Co and Li using $\mathrm{HCl}$ solution. The Co in the leached liquor was selectively extracted with PC-88A in kerosene and then as cobalt sulfate with high purity, while $\mathrm{Li}$ was obtained as $\mathrm{LiCO}_{3}$.

A combination of ultrasonic washing, acid leaching and precipitation was proposed by Li et al (2009a, 2009b) to recover Co from spent LIBs. The ultrasonic washing improved the recovery efficiency of $\mathrm{Co}$, reduced energy consumption as well as environmental pollution. 


\section{Macrothink}

This process was considered feasible for recycling spent LIBs for scale-up operation (Li et al., 2009a). A recycling process that combined hydrometallurgical and sol-gel steps in addition to other general steps was also used to recover $\mathrm{Co}$ and $\mathrm{Li}$ from LiBs. The acid media (hydrogen peroxide in $\mathrm{HNO}_{3}$ ) used enhanced the leaching efficiency. A gelatinous precursor was prepared by adding citric acid to the leaching liquor to obtain amorphous citrate precursor process (ACP), followed by pyrolysis to obtain pure crystalline $\mathrm{LiCoO}_{2}$ (Lee and Rhee, 2002).

\subsubsection{Combined Acid-Alkaline with Organic Solvents Process}

As a means of advancing the process of recycling spent lithium-ion batteries, combined acids-alkaline and organic solvents was used for safety, simplicity and other benefits observed in other methods. Lithium, $\mathrm{Ni}, \mathrm{Mn}$ and $\mathrm{Co}$ were leached from $\mathrm{LiMnNiCoO}_{2}$ using $\mathrm{HNO}_{3}$ and then precipitant, $\mathrm{NaOH}$ by Castillo et al (2002), while Consestabile et al (2001) also leached $\mathrm{LiCoO}_{2}$ with $\mathrm{HCl}$ and then precipitated the cations with $\mathrm{NaOH}$ solution. In similar steps, the batteries inner rolls were treated with $\mathrm{NaOH}$ to dissolve the aluminium foil to separate the cathode material powders from other components. The powder obtained was burnt to remove PVdF, followed by dissolution to produce sulfate solution. Cobalt in the solution was deposited as oxalate, while Acorga M5640 and Cyanex272 (di-(2,4,4 trimethyl pentyl) phosphoric acid) were used to selectively extract small quantities of $\mathrm{Cu}^{2+}, \mathrm{Co}^{2+}$ (Nan et al, 2005) and $\mathrm{Ni}^{2+}$ ions (Nan et al., 2006) in the solution. Wang et al (2009) selectively used $\mathrm{KMnO}_{4}$ to recover $\mathrm{Mn}$ as $\mathrm{MnO}_{2}$ and manganese hydroxide from the leaching liquor, while dimethylglyoxime was used to recover Ni. Cobalt was precipitated as cobalt hydroxide, while addition of a saturated $\mathrm{Na}_{2} \mathrm{CO}_{3}$ solution to the liquor precipitated $\mathrm{Li}$ as $\mathrm{Li}_{2} \mathrm{CO}_{3}$. The process can be represented by the flow-sheet in Figure 4. 


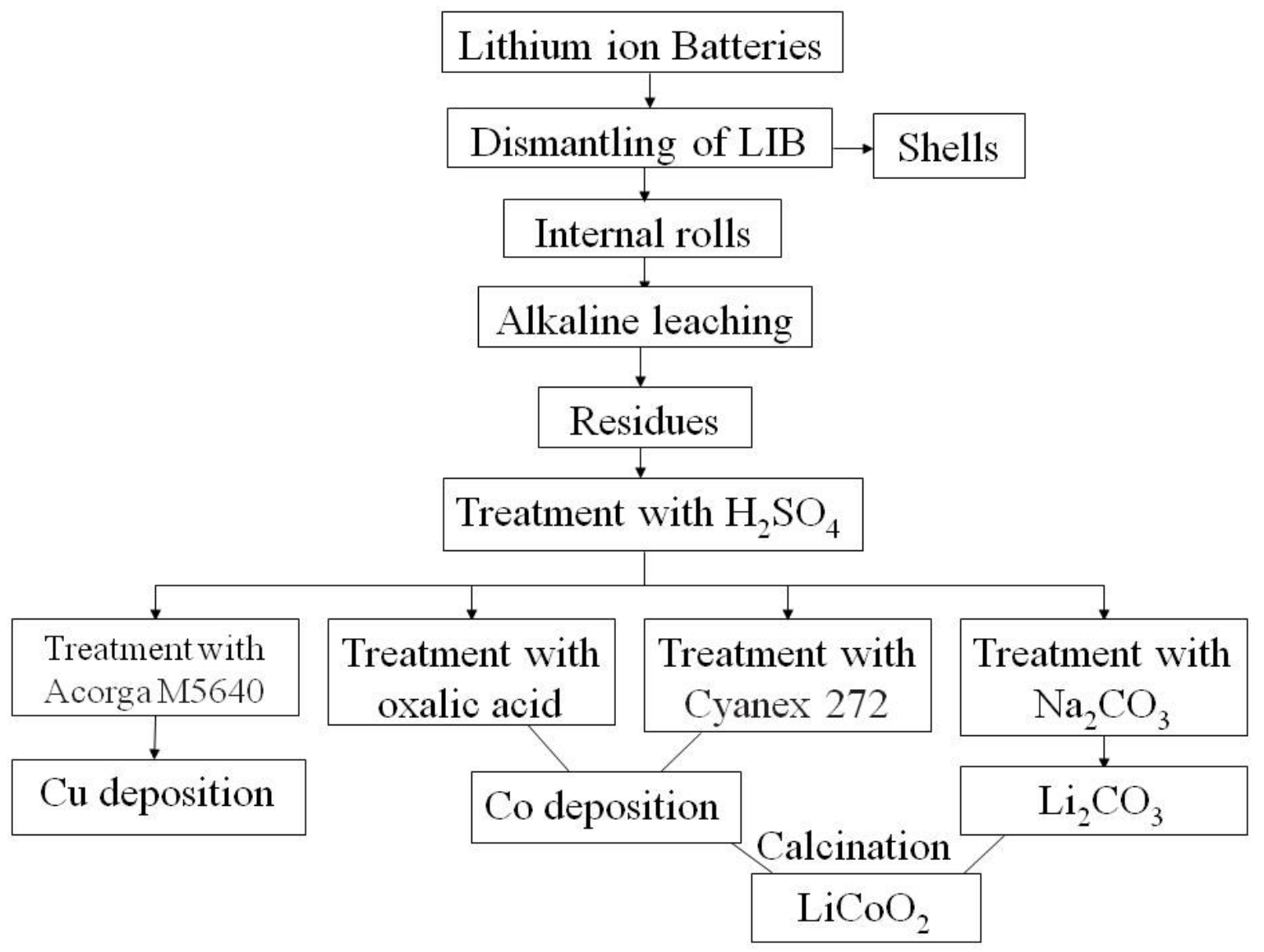

Figure 4. Flow sheet for general acid-alkaline with selective recovery and recycling of LiBs.

\subsubsection{Bio-Metallurgical Process}

Compared with the aforementioned pyrometallurgical, hydrometallurgical processes, bioprocess was considered as having higher efficiency, low cost and environmentally compatible (Bernardes et al., 2004; Xin et al., 2009). The process used bacteria and inorganic chemical solutions. For example, acidithiobacillus ferrooxidans utilized elemental sulfur and ferrous ion to produce metabolites, $\mathrm{H}_{2} \mathrm{SO}_{4}$ and ferric ion in the leaching medium to recover $\mathrm{Li}$ and $\mathrm{Co}$ from $\mathrm{LiCoO}_{2}$ of $\mathrm{LiBs}$. The metabolites enhanced the dissolution of metals from the batteries. Comparatively, bio-dissolution of Co was faster than Li (Mishra et al., 2008). Xin et al (2009) also recovered $\mathrm{Co}$ and $\mathrm{Li}$ from the spent LiBs through the same processes. However effective the procedure may be, the cost of culturing the enzymes or bacteria may somehow hinder its commercial operation.

\subsubsection{Electrochemical Process}

Electrochemical methods have been used to recover metals from the leached liquor of the cathode active materials of LiBs. Meanwhile, it was impossible to recover Ni directly by the method from the liquor obtained. Therefore, $\mathrm{Ni}$ was first separated from Co by solvent extraction, followed by its recovery through galvanostatic and potentiostatic electrowinning (Lupi and Pasquali, 2003). Also, Freitas and Garcia (2007) electrochemically recovered Co, while combination of the electrochemical and hydrothermal methods were used to recover 
both $\mathrm{Co}$ and $\mathrm{Ni}$ from $\mathrm{LiCoO}_{2}$ and $\left(\mathrm{LiCo}_{\mathrm{x}} \mathrm{Ni}(1-\mathrm{x}) \mathrm{O}_{2}\right.$ in the $\mathrm{Li}$ ion and $\mathrm{Li}$ polymer batteries, respectively (Lupi et al, 2005). The ionic equations for the electrochemical reactions of a divalent cation during electrolytic recycling process could follow:

Anode: $\mathrm{M}^{2+}+2 \mathrm{H}_{2} \mathrm{O} \longrightarrow \mathrm{MO}_{2}+4 \mathrm{H}^{+}+2 \mathrm{e}^{-}$

Cathode: $2 \mathrm{H}^{+}+2 \mathrm{e}^{-} \longrightarrow \mathrm{H}_{2}$

Overall: $\mathrm{M}^{2+}+2 \mathrm{H}_{2} \mathrm{O} \longrightarrow \mathrm{MO}_{2}+2 \mathrm{H}^{+}+\mathrm{H}_{2}$

\subsubsection{Pyrometallurgical Process}

The process chemically recovered valuable components of the waste materials or concentrates at elevated temperatures (Espinosa et al, 2004). Pauline et al (2008) fused the mixture of active mass (cathode and anode) and electrolyte with $\mathrm{KHSO}_{4}$ in a furnace. Although precaution was taking to avoid reduction of sulfate to $\mathrm{SO}_{2}$ of sulfide, industrial dumps like $\mathrm{CaF}_{2}, \mathrm{Ca}_{3}\left(\mathrm{PO}_{4}\right)_{2}$ and other byproducts were generated along with the desired products.

\section{Conclusion}

From the review so far, several attempts have been made to clean the environment and achieve the general objectives of waste sustainability and management. The chemical processes have been improved upon with great success recorded. However, the amount of chemicals involved in most of the multiple-steps used could render them economically unsuitable beside the effect of byproducts or other wastes generated that must be properly treated in conformity with the acceptable limit for the environments.

The use of suitable non-toxic organic solvents capable of dissolving the PVdF in the batteries to maximize the recovery values and enhance the reduction in the amount of HF gas released by pyrolysis before leaching has proved more environmentally compatible. We suggest that the inner materials of the LiBs be washed with suitable organic solvents to extract the toxic electrolyte mixture to avoid pollution caused by hydrolysis of $\mathrm{LiPF}_{6}$. Also, conversion of the electrolyte salt to useful products is achievable to minimize wastes generation.

\section{Acknowledgement}

We appreciate the support received from the School of Chemistry and Chemical Engineering, Southeast University, China. The expertise whose works are adopted is greatly appreciated.

\section{References}

Alfonso, J. C., Busnardo, N. G., \& Busnardo, R. G. (2004). In: Gaballah, I., Mishra, B., Solozobal, R., Tanaka, M. (Eds.) Proceedings of REWAS, (2004) Vol. III. TMS, Warrendale, Pennsylvania, USA, pp. 2783-2785.

Bankole, O. E., \& Lei, L. (2013) Silicon exchange effects of glassware on the recovery of $\mathrm{LiPF}_{6}$ : Alternative route to preparation of $\mathrm{Li}_{2} \mathrm{SiF}_{6}$, Journal Solid Waste Technology and Management (in press). 
Bernardes, A. M., Espinosa, D. C. R., \& Tenório, J. A. S. (2004). Recycling of batteries: a review of current processes and technologies. Journal of Power Sources, 130, 291-298. http://dx.doi.org/10.1016/j.jpowsour.2003.12.026

Castillo, S., Ansart, F., Laberty-Robert, C., \& Portal, J. (2002). Advances in the recovering of spent lithium battery compounds. Journal of Power Sources, 112, 247-254. http://dx.doi.org/10.1016/S0378-7753(02)00361-0

Contestabile, M., Panero, S., \& Scrosati, B. (1999). A laboratory-scale lithium battery recycling process. Journal of Power Sources, 83, 75-78. http://dx.doi.org/10.1016/S 0378-7753(99)00261-X

Contestabile, M., Panero, S., \& Scrosati, B. (2001) A laboratory-scale lithium-ion battery recycling process. Journal of Power Sources, 92, 64-69. http://dx.doi.org/10.1016/S 0378-7753(00)00523-1

Dewulf, J., Van der Vorst, G., Denturck, K., Van Langenhove, H., Ghyoot, W., Tytgat, J., \& Vandeputte, K. (2010). Recycling rechargeable lithium-ion batteries: Critical analysis of natural resource savings. Resources, Conservation and Recycling, 54, 229-234. http://dx. doi.org/10.1016/j.resconrec.2009.08.004,

Espinosa, D. C. R., Bernardes, A. M., \& Tenório, J. A. S. (2004). An overview on the current processes for the recycling of batteries. Journal of Power Sources, 135, 311-319. http://dx.doi.org/10.1016/j.jpowsour.2004.03.083

Freitas, M. B. J. G., \& Garcia, E. M. (2007). Electrochemical recycling of cobalt from cathodes of spent lithium-ion batteries. Journal of Power Sources, 171(2), 953-959. http://dx.doi.org/10.1016/j.jpowsour.2007.07.002

Gaines, L. (2011). Recycling of Li-Ion Batteries. Center for Transportation Research, Argonne National Laboratory, 1-42

Graham-Rowe, D. (2010). Cheaper, Stronger Lithium-Ion Batteries for Electric Vehicles. Energy News, pp1.

Hitachi Group Ltd. Lithium-Ion Batteries for Hybrid Electric Vehicles, 2011. Retrieved from http://www.hitachi.com

Johnson, M., \& Derrick, S. (2010). Pyrolysis: A method for mixed polymer recycling. Green Manufacturing Initiative, pp 1-21.

Kang J, Senanayake G, Sohn J, \& Myung S. S. (2010b). Recovery of cobalt sulfate from spent lithium-ion batteries by reductive leaching and solvent extraction with Cyanex 272 . Hydrometallurgy, 100, 168-171 http://dx.doi.org/10.1016/j.hydromet.2009.10.010

Kang, J., Sohn, J., Chang, H., Senanayake, G., \& Myung, S. S. (2010a). Preparation of cobalt oxide from concentrated cathode material of spent lithium-ion batteries by hydrometallurgical method. Advanced Powder Technology, 21, 175-179. http://dx.doi.org/10.1016/j.apt.2009.10.015 
Kondás, J., Jandová, J., \& Nemeckova, M. (2006). Processing of spent $\mathrm{Li} / \mathrm{MnO}_{2}$ batteries to obtain $\quad \mathrm{Li}_{2} \mathrm{CO}_{3}$. Hydrometallurgy, $\quad$ 84(3-4), 247-249. http://dx.doi.org/10.1016/j.hydromet.2006.05.009,

Kumar, A. (2011). The Lithium Battery Recycling Challenge. Waste Management World.

Lain, M. (2002). Recycling of lithium-ion cells and batteries. Journal of Power Sources, 97, 736-738. http://dx.doi.org/10.1016/S0378-7753(01)00600-0

Lee, C. K., \& Rhee, K-I. (2002) Preparation of $\mathrm{LiCoO}_{2}$ from spent lithium-ion batteries, Journal of Power Sources, 109, 17-21. http://dx.doi.org/10.1016/S0378-7753(02) 00037-X

Li, J., Shi, P., Wang, Z., Chen, Y., \& Chang, C.C. (2009a). A combined recovery process of metals in spent lithium-ion batteries. Chemosphere, 77(8), 1132-6. http://dx.doi.org/10.1016/j.chemosphere.2009.08.040,

Li, J., Zhang, Q., \& He, X. M. (2007). Preparation of $\mathrm{LiMn}_{1 / 3} \mathrm{Ni}_{1 / 3} \mathrm{Co}_{1 / 3} \mathrm{O}_{2}$ cathode materials from spent Li-ion batteries. Trans. Nonferrous Met. Soc. China, 17, s897-s901.

Li, J., Zhao, R., He, X., \& Liu, H. (2009b). Preparation of $\mathrm{LiCoO}_{2}$ cathode materials from spent lithium-ion batteries. Ionics, 15, 111-113. http://dx.doi.org/10.1007/s11581-008$0238-8$

Li, L., Ge, J., Chen, R., Wu, F., Chen, S., \& Zhang, X. (2010a). Environmental friendly leaching reagent for cobalt and lithium recovery from spent lithium-ion batteries. Waste Management, 30(12), 2615-2621. http://dx.doi.org/10.1016/j.wasman.2010.08.008

Li, L., Ge, J., Wu, F., Chen, R., Chen, S., \& Wu, B. (2010b). Recovery of cobalt and lithium from spent lithium ion batteries using organic citric acid as leachant. Journal of Hazard Materials, 176 (1-3), 288-93. http://dx.doi.org//10.1016/j.jhazmat.2009.11.026

Lupi, C., \& Pasquali, M. (2003). Electrolytic nickel recovery from lithium-ion batteries. Minerals Engineering, 16, 537-542. http://dx.doi.org/10.1016/ S0892-6875 (03)00080-3

Lupi, C., Pasquali, M., \& Dell'Era, A. (2005). Nickel and cobalt recycling from lithium-ion batteries by electrochemical processes. Waste Management, 25, 215-220. http://dx. doi.org /10.1016/j.wasman.2004.12.012

Mishra, D., Kim, D. J., Ralph, D. E., Ahn, J. G., \& Rhee, Y. H. (2008). Bioleaching of metals from spent lithium-ion secondary batteries using Acidithiobacillus ferrooxidans. Waste Managanement, 28(2), 333-8. http://dx.doi.org/10.1016/j.wasman.2007.01.010

Mitchell, R L. (2006). Lithium-ion batteries: High-tech's latest mountain of waste. Computerworld. Retrieved from http://blogs.computerworld.com/node/3285.

MTI Corporation. (2009). N-methylpyrrolidinone; N-methyl-2-pyrrolidone; Material Safety Data Sheet, 860 South 19th Street, Richmond, CA 94804. pp 1-7.

Nan, J., Han, D., \& Zuo, X. (2005). Recovery of metal values from spent lithium-ion batteries with chemical deposition and solvent extraction. Journal of Power Sources, 152, 278-284. 
http://dx.doi.org/10.1016/j.jpowsour.2005.03.134

Nan, J., Han, D., Yang, M., Cui, M., \& Hou, X. (2006). Recovery of metal values from a mixture of spent lithium-ion batteries and nickel-metal hydride batteries. Hydrometallurgy, 84(1-2), 75-80. http://dx.doi.org/10.1016/j.hydromet.2006.03.059

Nishi, Y. (2001). The Development of Lithium Ion Secondary Batteries. The Chemical Record, 1, 406-413. http://dx.doi.org/10.1002/tcr.1024

Paulino, J. F., Busnardo, N. G., \& Afonso, J. C. (2008). Recovery of valuable elements from spent Li-batteries. Journal of Hazardous Materials, 150, 843-849. http://dx.doi.org/ 0.1016/j.jhazmat.2007.10.048

Pietrelli, L., Bellomo, B., Fontana, D., \& Montereali, M. (2005). Characterization and leaching of $\mathrm{NiCd}$ and $\mathrm{NiMH}$ spent batteries for the recovery of metals. Waste Management. 25, 221-226. http://dx.doi.org/10.1016/j.wasman.2004.12.013

Robert, P. V. (2000). Dimethyl Sulfoxide (DMSO): A superior solvent underutilized because of a safety myth. Semiconductor Safety Association Annual Meeting, Arlington, VA.

Roth, E. P., \& Orendorff, C. J. (2012). How electrolytes influence battery safety. The Electrochemical Society Interface. pp 45-49.

Shin, S. M., Kim, N. H., Sohn, J. S., Yang, D. H., \& Kim, Y. H. (2005). Development of a metal recovery process from Li-ion battery wastes. Hydrometallurgy, 79, 172-181. http://dx.doi.org/10.1016/j.hydromet.2005.06.004

Sigma-Aldrich Corporation. (2011). Retrieved from http://www.sigmaaldrich.com

Wang, R. C., Lin, C. Y., \& Wu, S. H. (2009). A novel recovery process of metal values from the cathode active materials of the lithium-ion secondary batteries. Hydrometallurgy, 99, 194-201. http://dx.doi.org/10.1016/j.hydromet.2009.08.005

Wang, Y., Apelian, D., Mishra, B., \& Blanpain, B. (2011). Lithium Ion Battery Recycling: A $\mathrm{CR}^{3}$ Communication. Minerals, Metals and Materials Society, pp10.

Xin, B., Zhang, D., \& Zhang, X. (2009). Bioleaching mechanism of Co and Li from spent lithium-ion battery by the mixed culture of acidophilic sulphur-oxidising and iron-oxidising bacteria. Bioresource Technology, 100(24), 6163-6169. http://dx.doi.org/10.1016/j.biortech.2009.06.086,

Xu, J., Thomas, H. R., Francis, R.W., Lum, K. R., Wang, J., \& Liang, B. (2008). A review of processes and technologies for the recycling of lithium-ion secondary batteries. Journal of Power Sources, 177, 512-527. http://dx.doi.org/10.1016/j.jpowsour.2007.11.074

Zhang, P., Yokoyama, T., Itabashi, O., Suzuki, T. M., \& Inoue, K. (1998). Hydrometallurgical process for recovery of metal values from spent lithium-ion secondary batteries. Hydrometallurgy, 47, 259-271. http://dx.doi.org/10.1016/S0304- 386X(97)00050-9

Zhou, X., He, W-Z., Li, G-M., Zhang, X-J., Huang, J-W., \& Zhu, S-G. (2010). Recycling of 
Electrode Materials from Spent Lithium-ion Batteries, IEEE, 1-4. ISSN: 2151-7614. http:// dx.doi.org/10.1109/ICBBE.2010.5518015 